\title{
Balancing Act: Enabling Public Engagement with Sustainability Issues through a Multi-touch Tabletop Collaborative Game
}

\author{
Alissa N. Antle, Theresa Jean Tanenbaum, Allen Bevans, Katie Seaborn, and Sijie \\ Wang
}

\author{
Simon Fraser University, Surrey, BC, Canada \\ \{aantle, tess.tanen@gmail.com, alb19,kseaborn, swa50\}@sfu.ca
}

\begin{abstract}
Despite a long history of using participatory methods to enable public engagement with issues of societal importance, interactive displays have only recently been explored for this purpose. In this paper, we evaluate a tabletop game called Futura, which was designed to engage the public with issues of sustainability. Our design is grounded in prior research on public displays, serious games, and computer supported collaborative learning. We suggest that a role-based, persistent simulation style game implemented on a multi-touch tabletop affords unique opportunities for a walk-up-and-play style of public engagement. We report on a survey-based field study with 90 participants at the 2010 Vancouver Winter Olympics (Canada). The study demonstrated that small groups of people can be immediately engaged, participate collaboratively, and can master basic awareness outcomes around sustainability issues. However, it is difficult to design feedback that disambiguates between individual and group actions, and shows the temporal trajectory of activity.
\end{abstract}

Keywords: Public displays, sharable displays, digital tabletops, interactive surfaces, group interaction, multi-touch interaction, public participation, public engagement, social issues, sustainability, collaborative learning, serious games, simulations.

\section{Introduction}

Multi-touch displays are only just beginning to move from the research lab into public spaces [1]. The commodification of these technologies provides opportunities to design to support group participation with digital media in public venues, including hotel lobbies, bars, museums, and large scale sport and cultural events. Research about how to design walk-up-and-play style public displays on walls and tables has only just begun [2]. We do not yet know what design factors will contribute to their success [1]. What design considerations are critical to support walk-up-and-play group activities in public venues? What are the key design features that will enable public engagement with important societal issues on public displays?

The 2010 Vancouver Winter Olympics provided us with an opportunity to deploy a public display in a field study with hundreds of diverse participants. The topic of 
sustainable development was a key theme during this sports and cultural event. The topic has several features that make it an appealing choice when investigating the design space of public displays. Understanding the key elements of planning for a sustainable future in an urban area requires that the public understand the views of the different stakeholders involved, recognize the spatial nature of the issue, and have an awareness of the complex trade-offs involved in preserving the environment and developing facilities to support a growing population. In response to our research questions, this opportunity, and our prior work studying interaction on digital tabletops (e.g. [3]), we developed a digital media application implemented on a custom multi-touch tabletop called Futura: the Sustainable Futures Game.

In this paper, we discuss the problem of designing for engagement and small group interaction with a walk-up-and-play tabletop display in a busy public venue. Our hypothesis is that a multi-touch tabletop interface to a fast-paced, role-based simulation game can support groups of participants to meaningfully engage with content about social issues (e.g. sustainability) in a public space. We report on our field study at the 2010 Vancouver Winter Olympics. The study utilizes observational notes summarizing the reactions, responses and interactions of hundreds of players and a semi-structured survey with 90 study participants that was designed to provide insights and reveal issues with our design solution. Prior research based on the Futura game has included two observational studies focusing on learning [4], and a comparative study focusing on the effects of tangible and multi-touch tools on collaboration [5].

\section{Related Work}

This research builds on recent work in the domains of sharable public displays, multitouch tabletops, serious games and computer supported collaborative learning. We provide a summary of relevant articles here, and identify key concepts and issues in this design space.

\subsection{Shareable Public Displays}

Shareable displays are those interfaces that provide for multiple inputs and support group interaction [6]. While a large body of work focuses on the ambient nature of public displays (e.g. [7]), this is not our focus. Many other studies of sharable displays have occurred in semi-private spaces and involve groups of participants who know each other (e.g. [8]). Several findings are relevant. For example, an early study revealed the importance of supporting a walk-up-and-use style of interaction that is so self-explanatory that first-time users need no prior training [9]. An observational study on BlueBoard, a touch screen display for sketching that uses RFID to identify individuals, highlighted the importance of visibility of actions so that users can learn from watching each other's actions and the challenges of turn-taking [10]. While these findings may be relevant, our focus is on small groups of the public (who may be strangers) interacting with displays in large and busy public venues.

Research that focuses on large, multi-user wall displays in public settings is relatively rare due to technical difficulties with lighting and engaging first-time users 
[2]. However, several studies have revealed important factors to consider in design. One study raised the issue of how to encourage users to interact with the display in a busy setting [11]. The authors suggest positioning the display in a thoroughfare. Hornecker et al. identify entry and access points as important design considerations for displays in public spaces [12]. Entry points invite or entice people to interact with a display. Access points are interface characteristics that enable the user to interact, participate and join group interaction. Designs for public spaces must include both entry and access points to support walk-up-and-play.

In a detailed enthnographic study of CityWall, the authors identify and address issues of conflict management of digital objects and difficulties in turn-taking [2]. They suggest that successful designs must be playful, easy to use and novel. In addition, the authors suggest that designers should consider how to support parallel interaction; how to support learning through observing others; how enable a teacherapprentice approach; and the impact of the deployment on the surrounding architectural space. In a follow-up study, the authors identified and addressed several challenges in designing for engagement and parallel interaction [13]. They suggest using a multiple, 3D virtual worlds metaphor to support parallel interaction, reduce conflict, and help manage territoriality.

\subsection{Multi-touch Tabletop Displays}

Much research has been conducted on multi-touch and surface computing. However, the focus of this work has largely been on the details of touch-based interaction in collaborative workspaces and labs (e.g. [14-16]). Some findings are relevant to the design of public tabletops. Hornecker makes the case for the need for immediate apprehendability in public displays for learning [1]. Scott et al. make recommendations based on Computer Supported Collaborative Work studies concerning personal, group and storage territories [17]. Global actions should be visible and transparent. Local spaces should be configured according to functionality. Personal territories should be oriented to player location to ease reading. Occlusion that may occur in personal spaces should be considered. Storage territories should be provided for discrete, private objects.

\subsection{Serious Games}

Serious digital games have been designed to support informal and formal learning and training. An excellent overview that we draw on here in presented in [18]. Digital games provide visual digital information to one or more players, take input from players, process that input according to a set of programmed game rules, and change the digital information displayed back to players. A defining characteristic of a game is the set of game rules. Developers of serious games have hoped to harness the motivational power of games for learning. However, many educational games appear to be neither entertaining nor particularly successful in teaching players. These games suffer from two fundamental flaws: the people who design them often do not have traditional game design experience [19] and they do not properly translate knowledge, facts and lessons into the language of games, namely mechanics, rules, rewards and feedback [20]. 
A number of serious games have been developed that have environmentally conscious themes [21]. Games can potentially support an understanding of natural processes due to their use of procedural rhetoric to engage players in problem solving activities. In addition, games facilitate thinking procedurally about the consequences of actions on the environment. Microworlds are a simple but complete model of a domain or system that enables a person to "live" in that domain for some period of time. A simulation is a model of some domain [22]. An advantage of simulations for learning is that they provide direct access to subject matter or content that might not be readily accessible in the real world. A key assumption behind simulations is that users will "learn by doing". However, there are challenges in using game-based procedural rhetoric for learning [23]. Procedural rhetoric may elicit emotions that are inconsistent with the game's themes and goals, and in some cases the unexpected and emergent properties of the system can undermine the message of the game.

\subsection{Computer Supported Collaborative Learning (CSCL)}

Collaboration has been defined as "a process by which individuals negotiate and share meanings" and "a coordinated, synchronous activity that is the result of a continued attempt to construct and maintain a shared conception of a problem" [24]. This differs from cooperative activities in which learners may coordinate their efforts, but the work performed is primarily individual and in parallel [25]. Within education, the CSCL community has begun to research how multi-touch tabletops may support collaborative learning. Several studies have found that learners find tabletop interfaces engaging, enjoyable and playful [26]. However, findings have not always suggested learning gains. For further details of important elements required to support learning through collaboration, see $[4,5]$.

\section{Designing the Futura Tabletop Game}

\subsection{Design Challenges}

The high level design goal was to create an application that facilitates a shift in awareness or disposition around issues of sustainability in urban planning and development. Specifically, we are interested in helping the public understand the complexity of meeting the needs of a growing population while preserving the environment. We wanted to support the notion that sustainability is not simply achieved by making the right choices, but rather involves a complex negotiation between different stakeholders, in which short term decisions to meet human needs often have detrimental long term effects on the environment. A second important high level goal was that the installation had to be suitable for a fast throughput of large numbers of users at the Olympics cultural site. This type of massive public event introduces design constraints around scale, mobility, robustness and throughput of the tabletop installation.

In order to successfully enable groups to engage with interactive content about the issue of sustainable land use planning for an urban basin, we propose the following five specific design goals that must be met.

Learning: Individual users should gain an improved understanding of the complexity involved in balancing human and natural factors in land use planning for a 
sustainable future for an urban area. This outcome is conceptualized as something that is gained through a shift in awareness about the complexity of achieving sustainable development. It is not about learning concepts or facts.

Group Participation: The installation must promote active participation by small groups who may be strangers. Collaborative activity should involve equitable participation by each member of each group.

Walk-up-and-play: The activity must be immediately playable by small groups who can simply walk up and interact with the game, regardless of previous experience (or lack thereof) with new forms of interactive media.

Apprehendability: The content must be immediately understandable to people with a range of different knowledge levels about sustainability issues.

Appeal: The activity must appeal to a wide range of ages, cultures and preferences.

In previous work, we presented and discussed our design rationale specific to learning outcomes for the game [4]. In order to avoid duplication, in this paper we do not provide a detailed design rationale. Instead, we provide an overview of the game, and focus on presenting the results from our survey study. We contribute suggestions for generalizable design guidelines and two issues that must be overcome when designing collaborative, tabletop games that enable public engagement with the social issues.

\subsection{System Implementation}

Futura runs on a multi-touch version of EventTable, a custom multi-touch and tangible tabletop prototyping platform (initially described in [3]). Our system is housed in a modified IKEA wood and metal table with telescopic legs and a custom metal undercarriage that supports the camera, PC and projector hardware. The surface of the table's wood frame supports an Endlighten ${ }^{\mathrm{TM}}$ acrylic surface. Our sensing system relies on a diffused surface illumination (DSI) technique with four infrared strips, one on each side of the rectangular surface. We capture touches with a single web camera with an infrared filter on a wide angle lens embedded in a custom mount. The camera can cover an active sensing area of 85 by $68 \mathrm{~cm}$. The camera and firewire cable provides 30 frames per second (fps) data capture. We process camera data using Community Core Vision, an open source finger tacking software. The game application is written using an existing C\# multi-touch library called Breezy. A single short-throw projector provides a resolution of $1024 * 768$ pixels on the output surface of 103 by $68 \mathrm{~cm}$. We use a velum mat, attached below the Endlighten ${ }^{\mathrm{TM}}$ acrylic for the projection surface, leaving the top surface of the acrylic exposed, which results in better touch tracking.

\subsection{Game Description}

Futura is a multi-player simulation game played on a bar height tabletop (Figure 1). The game is designed to enhance people's awareness of the complexity of sustainable development planning for an urban area. The goal of the game is to work with the other players to support a growing population as time passes while minimizing negative impact on the environment. The game can be played by two to six players. The game is suitable for players of 7 years old and above. The game takes place in a locale that resembles the Fraser River basin (near Vancouver, Canada). 
There are three distinct roles that players can take: food, shelter, or energy supply. Each role has an individual toolbar oriented to each of the three sides of the table (Figure 2). The goal of the game is to support the population living in the area without having a catastrophically negative effect on the environment. Players must decide what kinds of food, shelter, or energy producing facilities to construct, and attempts to achieve balance in terms of the population support: neither wasting resources nor failing to provide for the population's needs.

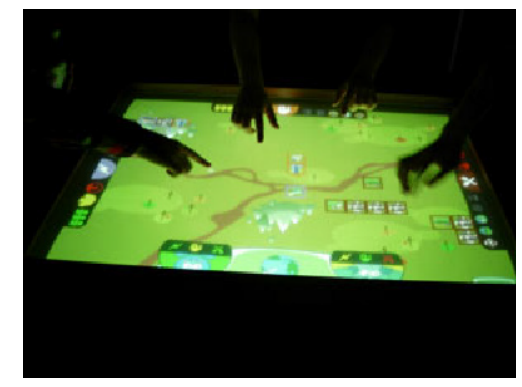

Fig. 1. Sustainability game on our custom tabletop

At the start of the game, there is a small base population present in the area. Over the course of the game, the population gradually grows. To meet the needs of the growing population, players drag facility tokens from the left side of their individual toolbars (e.g. housing, power plants, and farms) onto the map. For example, Figure 2 shows that single dwelling houses have been dragged from the left of the shelter toolbar onto the map. The game is won if players can add facilities in ways that meet the needs of a growing population without compromising the environment.

Each facility has a cost to build, can support a specific number of people and has a specific effect on the environment. Some facilities will produce more as time passes (i.e. will support a larger population), and some will produce less (i.e. support a smaller population). Information about different forms of environmental damage that may be caused by different facilities (e.g., physical waste, atmospheric pollution, chemicals in the water, pesticides in the food) are available through informational screens, which can be accessed before or during game play by touching and holding on each resource token.

The map interface provides both feedback of the global game state and feedback of individual tools. Each role has an icon that represents it on that role's toolbar and in the global display area (Figure 2). Food is a knife and fork. Shelter is a house. Energy is a lightning bolt. Each of the three toolbars has its role icon in the centre (left, bottom and right in Figure 2). A role toolbar is wide enough to be played by 1-2 players. Players use their toolbar to access information about facilities and can drag facilities from the toolbar to the map if they have enough money to pay for them.

As the game progresses, the environmental and population impacts of all the facilities currently on the board add up to a global environmental and a population effect. A global status console area on the fourth side of the table (top in Figure 2) shows this cumulative state of the game in terms of the environment (anthropomorphic tree) and population 
(face). The cumulative game state is also indicated through the changing colours of the main map interface (Figure 3) and the tone of the ambient soundtrack. Figure 4 shows the three states of global environment feedback. The tree changes its colour (green yellow, red) and facial expression to reflect three levels of environmental damage. The population's facial expression indicates how well the current population is being supported.

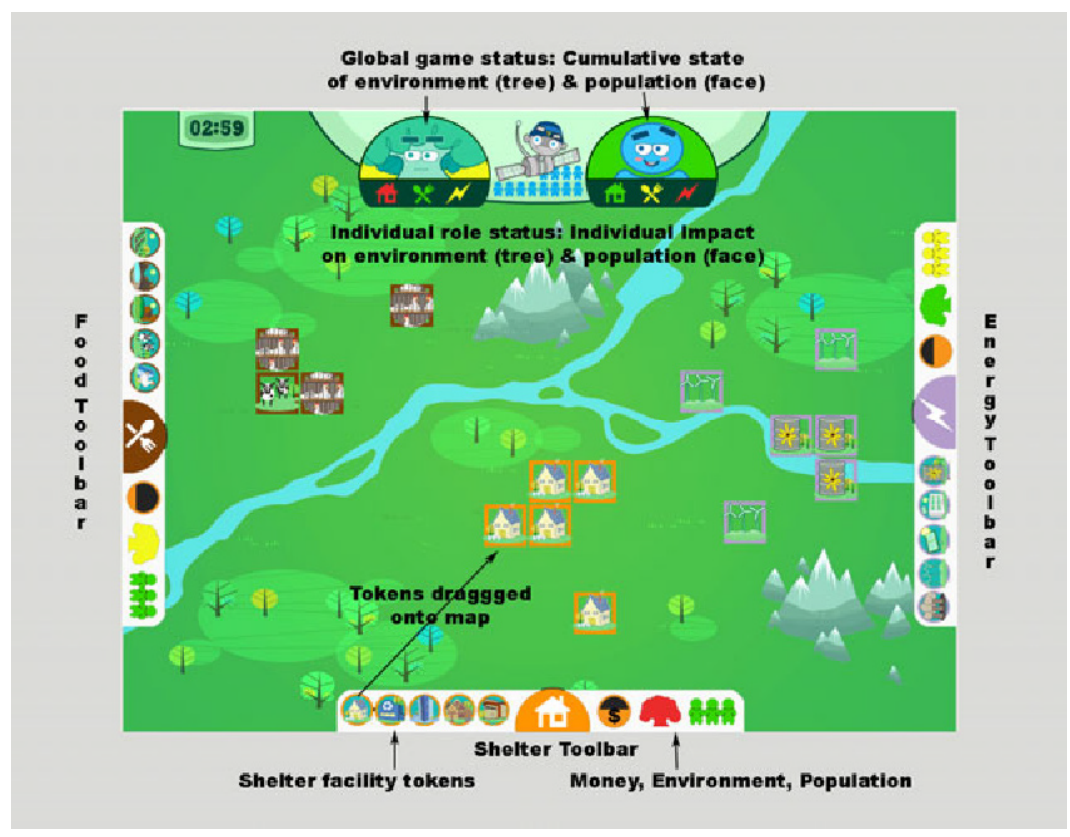

Fig. 2. Map with individual toolbars (left, bottom, right) and global display console (top)

The global display console also shows each role's status in terms of their individual impact on the environment up to this point in the game (indicated by the colour of role icon under tree) and their support of the current population up to this point in the game (indicated by the colour of role icon under face). For example, the red house on the left of the global display area indicates that the shelter player(s) has had a negative impact on the environment up to this point in the game. The game timer (top, left in Figure 2) shows the game time. The satellite is used to access game controls such as pause and reset.

If the environmental impact becomes too negative, natural disasters and other negative events begin to occur (e.g. Figure 5). While the game runs in real time (there is no turn-taking), there is a time-based cycle to the game. At regular intervals (every 10-20 sec), the players each receive an additional amount of money (shown in Figure 2, right of the shelter toolbar as an orange and black circle with a "\$" dollar sign). 


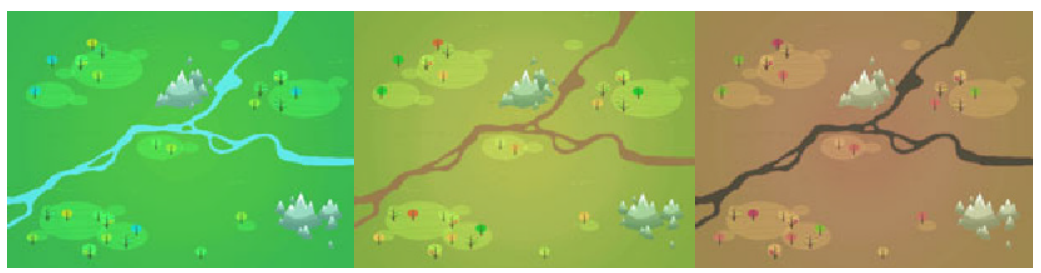

Fig. 3. Microworld map feedback states (colour changes)

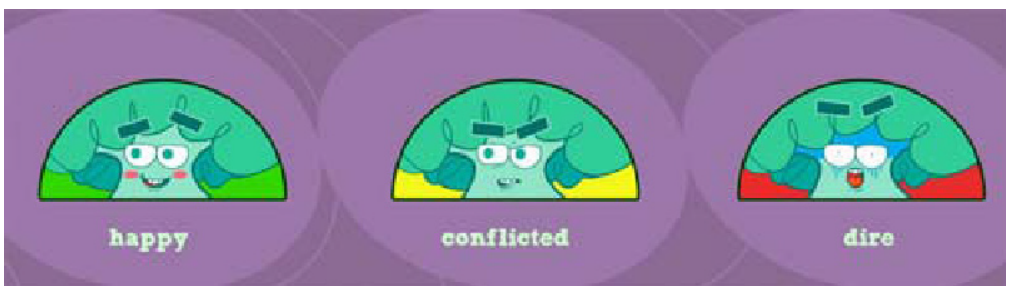

Fig. 4. Tree global environment feedback states (tree colour and facial expression)

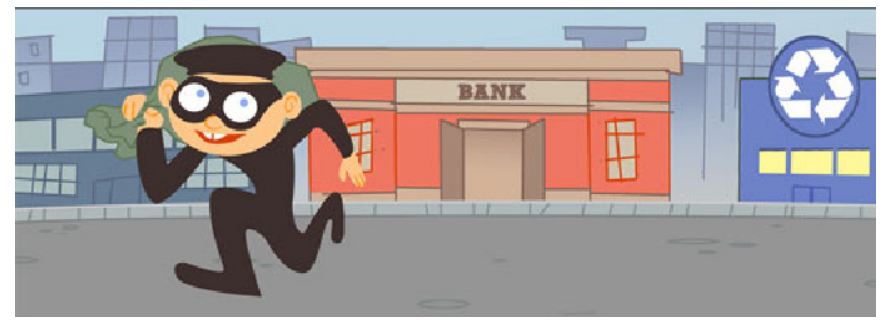

Fig. 5. World Event: Crime Spree (negative)

At the end of the game, a display informs the players of how they did. Summary information about group and individual outcomes is given through graphics and simple text. The game is designed to be played over and over in order to adjust strategies and learn from mistakes. It is possible, but non-trivial to end with a balanced game world. A video of the Futura project is available at http://www.antle.iat.sfu.ca/Futura/.

\section{Field Survey Study}

In this paper we focus on the design space of public engagement with tabletop displays and report on our field survey study. The goal of the survey-based field study was to determine if our version of a collaborative simulation game implemented on multi-touch tabletop met our design goals related to public engagement with the social issue of sustainable development planning. We also wanted to identify insights or issues with our design in order to better understand the key design factors that impact public interaction with a social issue through interactive displays. 


\subsection{Participants and Procedure}

We collected survey data from 90 participants aged nine and above. The age nine constraint was introduced by our ethics guidelines, not a design constraint. Participants were a convenience sample from the general population of visitors to one of the cultural sites at the 2010 Vancouver Winter Olympics. Our goal was to gather survey information from 80 to 100 players selected to ensure a range of ages, genders, social group configurations (e.g. family, teen groups, older adults) and cultures.

\subsection{Study Setting}

On the Olympics Surrey cultural site, Futura was positioned in a busy and narrow thoroughfare, as suggested in [11]. This afforded people walking up to it as part of their traversal of the space and then either playing, observing, asking to play or joining the queue if there was one. The variable lighting conditions meant that the game was only open after dark, roughly $5-8 \mathrm{pm}$.

\subsection{Survey Data Collection and Analysis}

Our survey focused on the five core areas based on our design goals. We asked both closed (Likert scale) and open questions to address the following design questions:

- Did participants gain a better understanding of the key issues related to sustainable development? What did they learn?

- Did participants actively work together to play the game?

- Did this type of collaboration help them learn about key issues related to sustainable development?

- Did participants "walk up and play" with little instruction? Did participants have usability problems with the multi-touch tabletop?

- Did participants understand how their choices impacted the game state in real time without turn-taking?

- Did participants of all ages understand the different kinds of information presented through territories on the tabletop interface (e.g. global information, individual player information)?

- Did the experience appeal to participants? Did they enjoy playing? Would they play again?

A seven-point Likert scale was used in the survey, where 1 was "strongly disagree" and 7 was "strongly agree". Closed question responses were analyzed using descriptive statistics (mean, median, standard deviation) in order to determine how well our sustainability tabletop game met our design goals. We also analyzed participants' written responses to open questions to search for common themes that would provide context for the quantitative findings. We also informally interviewed participants when the queue wasn't too long. We restrict our analysis to the survey data with the occasional mention of findings from informal interviews in cases where this provides context for our survey results. We searched for insights into what worked and sought to identify issues in areas where participants' responses were less positive. 


\subsection{Limitations}

This survey-based study utilizes a convenience sample and may not be generalizable. We also recognize that the Olympics is a specific kind of pubic event that attracts a specific visitor population. The cultural event site was free for everyone but likely only attracted certain types of users. The survey was not validated, although we have used several of the statements in previous work. These factors limit our ability to generalize our results. However, for the purposes of initially studying our design, and identifying important factors and challenges, we feel that the sample and survey instrument were adequate.

\section{Results}

Our results focus on providing evidence that we did or did not achieve our five design goals. Results provide validation for some of our design decisions, reveal insights about this design space, and uncover issues that must be addressed. We provide the survey statements and the mean, median and standard deviations of 90 participant responses for each closed question (Table 1). We follow this with quotes of written responses to open questions.

\subsection{Participant Profile}

Ninety participants completed our survey after playing our game one or more times. Forty-three percent of the players were between the ages of 14 and 18 years old, twenty-two percent of the players were between the ages of 9 and 13, and another twenty-two percent were between 19 and 29, making the primary age group those aged between nine and 30 (i.e. youth and young adult). Sixty-four percent of the players were female and the remaining thirty-six percent male.

\subsection{Overall Attitudes}

Overall participants found Futura fun and engaging to play and rated it a median value of 6/7 for enjoyment and repeat play (see statements S12, S13 in Table 1). Just fewer than half of the groups played more than once. This was determined in part by the length of the queue. All ages of audience, including children, teens and adults, enjoyed playing. For example, one adult player wrote, "It was educational yet very hands on and entertaining." A nine year old boy said, "It's fun. It's really challenging and that's why I like it."

\subsection{Experiences Based on the Survey}

Learning Outcomes. Most participants gained a somewhat better understanding of the importance of making sustainable land use decisions over time (S1) and gained a better understanding of how difficult it is to make sustainable land use choices over time (S2). Player's written responses to the question, "What did you learn?" varied. Many related to the theme of the difficulty of balancing human and natural needs - which was a learning outcome for the game. For example, participants responded with the following written responses: 
"How difficult it is to actually balance people vs. the environment and how easily the environment is damaged."

"It's hard to make both the environment and population happy."

"I learned that we need to help the environment and conserve every little thing we have. I also learned that building houses is expensive and difficult."

"That it's hard to keep the world in balance."

Group Participation and Interaction. Many participants somewhat agreed that they worked with the other players (S3) but there was some variation in responses. Participants were neutral about playing the game on their own and there was some variation in responses (S4). Participants somewhat agreed that working with other players helped them learn something new (S5). Most participants enjoyed playing with others (S6).

In response to "What was learned working with other players?", one player wrote, "You learned how to act as a team." Another wrote, "The groups responsible for each aspect of development need to communicate frequently and in great detail to make sure everything working well." Others wrote, "Cooperation is key. One person can't make a difference." and "Everyone needs to work together in order to gain some understanding."

We observed that some players who played the game more than once shifted from individual play to collaboration, including discussions with each other about how each player was doing in terms of supporting the population and minimizing the environmental impact, and would work out strategies together to keep the indicators in the green.

Walk-up-and-playability. Most participants could easily start to play by touching the screen and liked the multi-touch aspect of the game (S7). Many participants wrote that they enjoyed it because they could use their fingers to interact directly with the surface. Participants that had difficulty were usually young children, whose fingertips did not always register, or older adults who showed some hesitation to start. The variation in scores likely reflects some inconsistencies in touch tracking due to the angle of the sun in the late afternoon. Many participants understood and liked the real time (no turn-taking) style of game play (S8).

Apprehendability. Many participants quickly understood what the icons and symbols on the food or shelter or energy player toolbars represented and how to use them (S9). Fewer participants also understood the role-based feedback in the global status console (S10) and/or understood how their choices affected the game over time (S11). We note here that this self-report might not be reliable but discuss this finding below (see 6.2 Issues). Although we didn't explicitly ask about it, we observed that most participants quickly understood the world map metaphor. The map acted as a referential anchor for the players [27], enabling them to maintain a shared understanding of the game state by determining if they were winning or losing.

Appeal. Many participants wanted to play the game again (S12) and enjoyed playing the game (S13). Participants responded to "I enjoyed the game because __" with the following written responses such as:

"Fast, easy, educational." "Graphics and colours, move with fingers." "I got to meet new people." "Fun + thought provoking." 
Table 1. Survey results

\begin{tabular}{|c|c|c|c|}
\hline Statement & Mean & Median & Std Dev \\
\hline $\begin{array}{l}\text { S1. By playing this game I gained a better } \\
\text { understanding of the importance of making } \\
\text { sustainable land use decisions over time. }\end{array}$ & 5.3 & 5 & 1.04 \\
\hline $\begin{array}{l}\text { S2. By playing this game I gained a better } \\
\text { understanding of how difficult it is to make } \\
\text { sustainable land use choices over time. }\end{array}$ & 5.8 & 6 & 1.05 \\
\hline $\begin{array}{l}\text { S3. I actively worked with the other players while I } \\
\text { was playing the game. }\end{array}$ & 4.9 & 5 & 1.62 \\
\hline S4. I played the game mostly on my own. & 3.9 & 4 & 1.88 \\
\hline $\begin{array}{l}\text { S5. Working with other players helped me learn } \\
\text { something new about sustainable land use planning. }\end{array}$ & 5.1 & 5 & 1.34 \\
\hline S6. I enjoyed playing this game with other players. & 5.9 & 6 & 1.09 \\
\hline $\begin{array}{l}\text { S7. I liked playing this game because I could use my } \\
\text { fingers to move objects around on the tabletop map. }\end{array}$ & 5.7 & 6 & 1.52 \\
\hline $\begin{array}{l}\text { S8. I liked playing this game because the game was } \\
\text { played out in real time without turn-taking. }\end{array}$ & 6.1 & 6 & 0.97 \\
\hline $\begin{array}{l}\text { S9. I used the food or shelter or energy player toolbar } \\
\text { on my side of the table to help me play the game. }\end{array}$ & 5.9 & 6 & 0.91 \\
\hline $\begin{array}{l}\text { S10. I used the global impact information display at } \\
\text { the top of the tabletop map to help me play the game. }\end{array}$ & 5.3 & 6 & 1.49 \\
\hline $\begin{array}{l}\text { S11. I could see how my choices affected the game } \\
\text { over time by using both the toolbar and global impact } \\
\text { display. }\end{array}$ & 5.5 & 6 & 1.32 \\
\hline $\begin{array}{l}\text { S12. If I had the chance, I'd like to play this game } \\
\text { again. }\end{array}$ & 5.7 & 6 & 1.19 \\
\hline S13. I enjoyed playing this game. & 6.0 & 6 & 0.97 \\
\hline
\end{tabular}

\section{Discussion}

Our goals were to understand if a multi-touch surface application in a public space could support groups of users to walk up and engage with an activity about sustainability, and what design factors would be critical for its success. Our survey results are largely positive and provide evidence that it is possible to design a multitouch tabletop game to engage the public with the issue of sustainability at a busy public event. While we find that the survey results are very positive, we interpret this cautiously. It is possible that the nature of the venue for the study combined with the novelty of the game lead participants to be overly positive.

Analysis of previous work in this design space combined with examination of closed and open survey question responses allow us to suggest five design features of importance that can be used to guide future designs, and to identify two issues with our design that must be overcome in future designs. 


\subsection{Important Design Features}

Design choices result in specific design features, which in turn provide opportunities for interaction, which in turn create, shape, and constrain opportunities for public engagement with a tabletop game. Specific kinds of interactions ensure that the design meets the design goals related to learning, group participation, walk-up-andplayability, apprehendability and appeal. For example, choices about the approach and model for learning are made and instantiated in the features of the core mechanic of the game (e.g. learning through a simulation) and the user interface design (e.g. feedback providing playful guidance). Choices about the kind of group interaction enabled are made and instantiated in the game mechanic (e.g. cooperative), game rules (no turn-taking), and reward structure (winning requires collaboration).

We propose that the following design features are critical to the success of a learning game that engages the public in a serious social issue such as sustainable development. We also suggest that this unique combination of design features works well together to enable walk-up-and-playability. Completely meeting the goal of apprehendability requires future work.

We summarize some of our design decisions as general guidelines. In line with our exploratory survey methodology, we suggest that these guidelines are meant as considerations rather than prescriptive heuristics. They are also meant to be considered as a set, rather than individually. We suggest that it is the combination of this set of design features that lead to our positive results rather than any one of them.

Entry through Fast Play in a Microworld. Drawing on Rieber's work in blending microworlds, simulations, and games [22], the game invites people to participate in the issue of sustainable development by directly experiencing a simulated land development game in a microworld. Multi-touch interaction on a horizontal surface enables fast play by multiple players. The action on a colourful map surface draws and sustains attention in a crowded space. The four sides of the table provide entry points [12] for players (three sides) or spectators (fourth side). A hand icon on the introduction screens may have promoted touching the displays as reported in [1]. Hundreds of people played Futura during the event. We found that people played when there was no one playing (e.g. when it first opened), after taking a spectator role while waiting for a turn, and even when there was a queue. The only deterrent to entry seemed to be the length of the queue and the crowded space around the table.

Guideline. Combining a simulation microworld style of game on a multi-touch tabletop enables people to quickly and easily enter the play space.

Access through Roles and Territories. Futura invites people to participate in the game by providing access points [12] through roles and associated personal territories (i.e. toolbars) [17]. Some participants negotiated roles by referring to toolbars, which act as objects of shared negotiation [28], while others walked up and played the role on the side of the table where they stood. Survey data indicated that most players understood how to use the individual toolbars. Placing toolbars with a static orientation is contrary to the prevailing design guidelines that suggest content should be dynamically oriented to a user's position [17]. In Futura, a static orientation ensures that each player is responsible for one role and one corresponding toolbar territory in a collaborative activity. 
Guideline. Providing individual roles and territories through role-based toolbars on three of the four sides of the tabletop enables people to quickly choose a role and access the game through that role and territory.

Encoding Learning in Game Structure, Rewards and Feedback. In the sphere of public engagement in social issues, outcomes are informal and our survey data indicated that our goals were largely met. We suggest that a unique feature of our game is that the design addresses the problem of unreliable learning gain in collaborative games [26] by encoding learning in the game mechanics as suggested in [20]. We use a replayable game structure where winning the game both requires and rewards achievement of learning outcomes. The mechanics of the game were balanced in such a way that it was only possible to win by understanding the impact of different development choices on the environment. However, losing the game also advances learning by confronting players with the complexity of sustainable development planning. The game is currently paced so that it completes within about three minutes of play. This allows players to play and lose multiple times, and to observe the impact of different choices and decisions during this process. By keeping the time investment short, we hoped to reduce the attachment to the outcome that comes from deep sustained play in video games. Our survey showed that many participants wanted to play over and over (S12).

Another important design decision was that losing is not stigmatized in any way. Although most participants lost multiple times, they still responded that they enjoyed the game (S13). The world events, such as crime spree (Figure 5), were viewed as cute and fun, and provided an indication that players were losing the game. The end state feedback is presented in informative displays that support productive discussion about what is required to keep the world in balance in future play (Figure 7).

Guidelines. The combination of the following guidelines enabled learning from game play. We suggest that these guidelines are relevant to educational games in general, and that the affordances of a multi-touch tabletop enhances their effectiveness.

- Using a fast, repeatable game style encourages repeat play and motivates wanting to win.

- Designing the game mechanic in a way that winning requires learning outcomes to be met and it is easy to determine if learning outcomes are met.

- Providing playful feedback reduces the stigma of losing and motivates learning through repeat play.

- Designing the game mechanic in a way that losing furthers learning outcomes and ensures some learning even from losing.

Playing without Turn-Taking. A simulation style game supports simultaneous play and avoids the issue of participants having to work out turn-taking protocols [17, 22]. Participants can drag and drop resources as fast as they can if they have enough money. The survey indicated that most players liked this style of play (S8). However, this style of game play results in some unforeseen effects described under Issues below.

Guideline. Using multi-touch interaction enables fast entry to simultaneous play, which is well suited to walk-up-and-play style games in public spaces. 
Facilitating Collaboration through Game Mechanics and Interface Design. Players do not compete against each other in the game, but must work together. We balanced the game engine so that any one player had the ability to cause the whole group to lose. This meant that players who had mastered one aspect of the system had incentive to talk to other players in order to win. By encouraging the players to explain their learning to each other, we provided them with an opportunity to reinforce that learning. Written comments indicated that some participants found it difficult to win through collaboration. However, the survey results indicated that they did largely work together (S3-S6), although there was variation in responses.

Another design choice that supports collaboration is that at any point in the game, any player can look at the global or individual toolbar displays to see how the other players are doing, and how they are affecting the world. No information is hidden between players. In addition, the size of the tabletop makes it possible for most people to reach across the table and interact with each other's toolbars, which creates opportunities for negotiation [28] that we see as central to collaboration. However, the distances between all three toolbars make it impossible for any one player to reach all three toolbars simultaneously and control the game. In these ways, we support learning by observing others and a teacher-apprentice model as suggested in [2]. We also suggest that conflict was minimized simply by not rewarding it in the game rules. Players who did not collaborate, could not win.

Guidelines. The combination of the following guidelines enabled collaboration. We suggest that these guidelines are relevant to collaboration in general, and that the affordances of a multi-touch tabletop enhances their effectiveness.

- Requiring each player to individually win for the group to win facilitates collaboration.

- Providing toolbars reachable by two of the three players reduces single player "take-over".

- Providing a single group display that is visible to all players supports group communication.

- Using a single large map world interface supports players to come to a shared understanding of the game state.

\subsection{Issues}

Issues were identified by looking at survey statements with lower mean scores and higher variation, and related written comments that allow us to infer areas that may need improvement. We identified two important issues that must be resolved in this design space and provide some suggestions for resolution.

Balancing Individual and Group Game Feedback. Meeting our design goal of apprehendability requires that we reduce dependence on prior knowledge and make information understandable by players from a broad age range. To address this goal, we used visual symbols and simple images to communicate information. The size of the tabletop (103 by $68 \mathrm{~cm}$ ) provides ample space for clear symbols and thumbnails, as well as for both individual toolbars and group display spaces. For example, we use interface metaphors including a world map, tree, and face that change colour to reflect 
cumulative, global game states. We also use house, knife and fork (food), and lightning bolt (energy) symbols to represent how well the population is supported by each role or facility type. While most players understood and used the individual toolbars (S9), not all understood that the global display represented group progress (variation in responses for S10) and each role's individual contribution to group progress. The game requires individual play and rewards group participation. However, the real time style of play made it difficult for players to distinguish between individual and group effects, which is an important meta-cognitive strategy required for collaborative learning [29].

Understanding Short versus Long Term Effects. Participants expected to see an immediate effect of each action taken. Many players did not understand the relationship between the history of their actions and the cumulative game state. This may account for the variation in responses for S10. Many participants mentioned this in our informal interviews. However, the correct simulation model is that all actions of the players impact the game state cumulatively over time. We have encoded the correct model into the game mechanic but found it difficult to find a simple way to communicate short term impact and cumulative temporal effects to players through graphical interface feedback. In order to achieve apprehendability by using simple colour changes of the map and by using tree and face symbols to represent game states, we found it difficult to communicate the temporal trajectory of cumulative activity effectively to players. This trade-off may need to be reconsidered.

\section{Conclusion}

Research that contributes to understanding how to design for public "walk-up-andplay" tabletop displays has only just begun. Our research contributes to this effort through the design, implementation, and deployment of an exemplar public "walk-upand-play" tabletop game. The use of such displays to engage the public in discussions about issues of societal importance is also a new field of study. Our findings from the field study of Futura demonstrate that a fast-paced, role-based, simulation, tabletop game can effectively engage the public in learning about the complexity of sustainability development. In our approach, we wove together knowledge from multiple domains to make design decisions about learning content, game mechanics, as well as information, interaction and interface design to create a tabletop and application that met goals about learning, group interaction, playability, apprehendability, and appeal.

When designing for this space, we suggest that entry points can be achieved by using a colourful map-based microworld on a multi-touch tabletop platform. While previous work suggests dynamic orientation of territories [23], we use static personal territories to enable role-based play, which provides interface access points to encourage immediate playability and eliminates the need for turn-taking. However, our analysis revealed tension between using real time play and effectively supporting learning about how individual versus group actions affected the game outcomes. We encode learning content in the game mechanics of a simple simulation game where both winning and losing enable learning outcomes. We use a predominantly graphical style of information presentation to support apprehendability. We use a map as a 
referential anchor and shared displays to support collaboration. However, our analysis revealed a tension between using a largely visual approach to information and interface design and effectively supporting learning about the cumulative effects that short term actions have on sustainability. Future work is needed to address these design trade-offs. We suggest that our findings are applicable to researchers and designers involved in public display design and public engagement campaigns using new media channels.

Acknowledgments. This research was funded by an NSERC RTI and a GRAND NCE grant (Canada).

\section{References}

1. Hornecker, E.: "I don't understand it either, but it is cool" - -Visitor interactions with a multi-touch table in a museum. In: Tabletop 2008, pp. 113-120. IEEE, Los Alamitos (2008)

2. Peltonen, P., Kurvinen, E., Salovaara, A., Jacucci, G., Ilmonen, T., Evans, J., Oulasvirta, A., Saarikko, P.: It's Mine, Don't Touch!: interactions at a large multi-touch display in a city centre. In: CHI 2008, pp. 1285-1294. ACM Press, New York (2008)

3. Antle, A.N., Motamedi, N., Tanenbaum, K., Xie, L.: The EventTable technique: Distributed fiducial markers. In: TEI 2009, pp. 307-313. ACM Press, New York (2009)

4. Antle, A.N., Bevans, A., Tanenbaum, T.J., Seaborn, K., Wang, S.: Futura: Design for collaborative learning and game play on a multi-touch digital tabletop. In: TEI 2011, pp. 93-100. ACM Press, New York (2011)

5. Speelpenning, T., Antle, A.N., Doring, T.v.d.H., E.: Exploring how a tangible tool enables collaboration in a multi-touch tabletop game. In: INTERACT (in press, 2011)

6. Sharp, H., Rogers, Y., Preece, J.: Interaction Design. John Wiley \& Sons, New York (2007)

7. Vogel, D., Balakirshnan, R.: Interactive public ambient displays: transitioning from implicit to explicit, public to personal, interaction with multiple users. In: UIST 2004, pp. 137-146. ACM Press, New York (2004)

8. Huang, E., Mynat, E.: Sharable displays: Semi-public displays for small, colocated groups. In: CHI 2003, pp. 49-56. ACM Press, New York (2003)

9. Elrod, S., Bruce, R., Gold, R., Goldberg, D., Halasz, F., Janssen, W., Lee, D., McCall, K., Pedersen, E., Pier, K., Tang, J., Welch, B.: Liveboard: a large interactive display supporting group meetings, presentations, and remote collaboration. In: CHI 1992, pp. 599-607. ACM Press, New York (1992)

10. Russell, D.M., Drews, C., Sue, A.: Social aspects of using large public interactive displays for collaboration. In: Borriello, G., Holmquist, L.E. (eds.) UbiComp 2002. LNCS, vol. 2498, pp. 229-236. Springer, Heidelberg (2002)

11. Brignull, H., Rogers, Y.: Enticing people to interact with large public displays in public spaces. In: INTERACT, pp. 17-24. IOS Press, Amsterdam (2003)

12. Hornecker, E., Marshall, P., Rogers, Y.: From entry to access - How shareability comes about. In: DPPI 2007, pp. 328-342 (2007)

13. Jacucci, G., Morrison, A., Richard, G.T., Kleimola, J., Peltonen, P., Parisi, L., Laitinen, T.: Worlds of information: designing for engagement at a public multi-touch display. In: CHI 2010, pp. 2267-2276. ACM Press, New York (2010) 
14. Forlines, C., Wigdor, D., Shen, C., Balakrishnan, R.: Direct-touch vs. mouse input for tabletop displays. In: CHI 2007, pp. 647-656. ACM Press, New York (2007)

15. Wu, M., Balakrishnan, R.: Multi-finger and whole hand gestural interaction techniques for multi-user tabletop displays. In: UIST, pp. 193-202. ACM Press, New York (2003)

16. Rogers, Y., Hazlewood, W., Blevis, E., Lim, Y.K.: Finger talk: Collaborative decisionmaking using talk and fingertio interaction. In: CHI 2004, pp. 1271-1274. ACM Press, New York (2004)

17. Scott, S.D., Carpendale, M.S.T., Inkpen, K.M.: Territoriality in collaborative tabletop workspaces. In: CSCW, pp. 294-303. ACM Press, New York (2004)

18. Kirriemuir, J., McFarlane, A.: Literature Review in Games and Learning. Futurelab (2004)

19. Van Eck, R.: Digital game-based learning: It's not just the digital natives who are restless. EDUCAUSE Review 41, 16-30 (2006)

20. Jenkins, H., Hinrichs, R.: Games to Teach Project, http: / / icampus.mit.edu/projects/GamesToTeach.shtml

21. Chang, A.Y.: Playing the environment: Games as virtual ecologies. In: DAC 2009 (2009), http: / / www. escholarship.org/uc/item/46h442ng?display=all

22. Rieber, L.P.: Seriously considering play: Designing interactive learning environments based on the blending of microworlds, simulations, and games. Educational Technology Research and Development 44, 43-58 (1996)

23. Treanor, M., Mateas, M.: Newsgames: Procedural rhetoric meets political cartoons. In: DiGRA (2009),

http: / /www.digra.org/dl /display_html?chid=http: / / www.digra.o $\mathrm{rg} / \mathrm{dl} / \mathrm{db} / 09300.09505 . \mathrm{pdf}$

24. Roschelle, J., Teasley, S.: The construction of shared knowledge in collaborative problem solving. In: CSCL, pp. 69-197. Springer, Heidelberg (1995)

25. Dillenbourg, P.: What do you mean by "collaborative learning"? In: Dillenbourg, P. (ed.) Collaborative Learning: Cognitive and Computational Approaches, pp. 1-16. Elsevier Science, New York (1999)

26. Piper, A.M., Hollan, J.D.: Tabletop displays for small group study: Affordances of paper and digital materials. In: CHI 2009, pp. 1227-1236. ACM Press, New York (2009)

27. Clark, H.H., Brennan, S.E.: Grounding in communication. In: Resnick, L.B., Levine, J.M., Teasley, S.D. (eds.) Perspectives on Socially Shared Cognition, pp. 127-149. American Psychological Association, Washington, DC (1991)

28. Suthers, D., Hundhausen, C.: An empirical study of the effects of representational guidance on collaborative learning. Journal of the Learning Sciences 12, 183-219 (2003)

29. Duffy, T.M., Dueber, B., Hawley, C.L.: Critical thinking in a distributed environment: A pedagogical base for the design of conferencing systems. In: Bonk, C.J., King, K.S. (eds.) Electronic Collaborators: Learner-centered Technologies for Literacy, Apprenticeship, and Discourse, pp. 51-78. Lawrence Erlbaum Associates, Mahwah (1998) 